\title{
Repression of drought-induced cysteine-protease genes alters barley leaf structure and responses to abiotic and biotic stresses
}

\author{
Andrea Gomez-Sanchez, Pablo Gonzalez-Melendi, M. Estrella Santamaria, Vicente Arbona, \\ Angeles Lopez-Gonzalvez, Antonia Garcia, Goetz Hensel, Jochen Kumlehn, \\ Manuel Martinez and Isabel Diaz
}

\begin{abstract}
To survive under water deficiency, plants alter gene expression patterns, make structural and physiological adjust-ments, and optimize the use of water. Rapid degradation and turnover of proteins is required for effective nutrient recycling. Here, we examined the transcriptional responses of the C1A cysteine protease family to drought in barley and found that four genes were up-regulated in stressed plants. Knock-down lines for the proteaseencoding genes HvPap-1 and HvPap-19 showed unexpected changes in leaf cuticle thickness and stomatal pore area. The efficiency of photosystem II and the total amount of proteins were almost unaltered in stressed transgenic plants while both parameters decreased in stressed wild-type plants. Although the patterns of proteolytic activities in the knock-down lines did not change, the amino acid accumulation increased in response to drought, concomitant with a higher ABA content. Whilst jasmonic acid (JA) and JA-lle concentrations increased in stressed leaves of the wild-type and the HvPap-1 knock-down lines, their levels were lower in the HvPap-19 knock-down lines, suggesting the involvement of a specific hormone interaction in the process. Our data indicate that the changes in leaf cuticle thickness and stomatal pore area had advantageous effects on leaf defense against fungal infection and mite feeding mediated by Magnaporthe oryzae and Tetranychus urticae, respectively.
\end{abstract}

Keywords: Abiotic/biotic stress, cysteine-protease, drought, leaf cuticles, stomata, water deprivation. 


\section{Introduction}

Drought is considered to be one of the most critical threats to agriculture worldwide, and is responsible for the largest losses of crops. Plants defend themselves against adverse conditions, and in particular to drought, by activating an orchestrated and highly regulated molecular network that triggers biochemical, physiological, and morphological changes to minimize damage. Under drought stress, stomata are closed to prevent transpiration, which limits $\mathrm{CO}_{2}$ uptake, reduces photosynthesis, and subsequently impairs plant growth. Osmotically active compounds and protective proteins accumulate and sink/ source allocation is adjusted. Cuticles become thicker due to an increase of both cutin monomers and waxes to avoid water loss, the shoot-to-root ratio decreases, and a deeper root system develops. These events are regulated by changes in the hormone content, mainly by altering the abscisic acid (ABA) levels, which act as key regulator of the global process (Osakabe et al., 2014; Shi et al., 2016; Bi et al., 2017; Xue et al., 2017). Drought stress brings about premature plant senescence, which usually leads to a reduction in the canopy size and to a drop in yield in annual crops. The impact is even more drastic when water deficit occurs during the reproductive or grain filling stages (Barnabás et al., 2008; Mahalingam, 2017).

High protease activities are closely associated with plant responses to different stresses, particularly water deficit, and they enhance the protein turnover required for metabolic processes and nutrient recycling (Khanna-Chopra et al., 1999; Beyene et al., 2006; Kidric et al., 2014; Botha et al., 2017). Droughtsensitive plants have a higher proteolytic activity than resistant ones (Beyene et al., 2006; Simova-Stoilova et al., 2010). Plant proteases are key players involved in these proteolytic events that are linked to the responses to stress. The $\mathrm{C} 1 \mathrm{~A}$ cysteine-protease (CysProt) family, also known as papain-like CysProt, is one of the most abundant (Rawlings et al., 2018). Martinez and Diaz (2008) grouped the C1A CysProt family as cathepsin L-, B-, $\mathrm{H}-$, and $\mathrm{F}-$ like based on their gene structure and relationships. Although most of their members still have unknown functions, some reports have demonstrated the participation of the C1A family in senescence, abscission, autophagy, programmed cell death, protein mobilization in seeds and tubers, and response to different stresses (van der Hoorn, 2008;Martínez et al., 2012; Diaz-Mendoza et al., 2016a, 2016b; Velasco-Arroyo et al., 2016 ; Sueldo and van der Hoorn, 2017; Bárány et al., 2018). The upregulation of C1A CysProt genes is essential for protein breakdown throughout stress responses by triggering reorganization of metabolism, remodelling of cell protein compounds, degradation of damaged or unnecessary proteins, and remobilization of nutrients (Rabbani et al., 2003; Parrott et al., 2010; Guo and Gan, 2012; Roberts et al., 2012; Díaz-Mendoza et al., 2014; Wang et al., 2018). Papain-like CysProts not only respond to abiotic stresses but also to biotic ones mediated by pathogens and pests (Kempema et al., 2007; Shindo and van der Hoorn, 2008; Diaz-Mendoza et al., 2017; Thomas and van der Hoorn, 2018).

Most research carried out so far on the relationship between CysProt and drought has examined the function of individual members. Thus, Zang et al. (2010) demonstrated that the overexpression of the Triticum aestivum CysProt (TaCP) gene confers greater tolerance to water deficit than in wild-type plants. Likewise, the ectopic expression of the sweet potato CysProt (SPCP2) gene in Arabidopsis alters plant growth and enhances the tolerance to drought and/or salt stress (Chen et al., 2010). Conversely, CysProt may play the opposite role, as demonstrated by increased sensitivity to drought stress and altered phenotypic traits observed in transgenic Arabidopsis plants constitutively expressing the SPCP3 gene (Chen et al., 2013). C1A CysProt activities can be inhibited by a specific group of molecules termed cystatins (Benchabane et al., 2010; Martinez et al., 2012, 2016). Accumulating evidence suggests that cystatin over-expressing plants with less CysProt activity present more tolerance to drought (Zhang et al., 2008; Quain et al., 2014; Tan et al., 2017). Recently, Velasco-Arroyo et al. (2018) have examined the effects of cystatins on plant behaviour under a deficit watering regime by independently silencing two barley drought-induced cystatin genes, $I c y-2$ and $I c y-4$.

Barley (Hordeum vulgare) is an excellent model to study drought-associated events in plants due to its high capability to adapt to severe conditions (Dawson et al., 2015). The participation of the barley C1A CysProt family members in different physiological processes and their roles in plant growth under stress conditions have already been established, for example in $\mathrm{N}$ starvation, darkness, high carbohydrate levels, and pathogen and pest attack (Martinez et al., 2009, 2012; Parrott et al., 2010; Diaz-Mendoza et al., 2016b; Velasco-Arroyo et al., 2016; Santamaria et al., 2018a, 2018b), and a recent study has highlighted the function of specific barley cystatins related to responses to drought (Velasco-Arroyo et al., 2018)

This work examines the responses of the entire C1A CysProt family in barley leaves to drought, and characterizes two of the genes that are up-regulated, namely HuPap-1 (HORVU5Hr1G082810) and HvPap-19 (HORVU4Hr1G010390). Unexpected changes in leaf cuticles and stomata were found when the expression of these drought-induced genes was reduced, and the consequences for plant defense responses of these structural alterations are examined and discussed.

\section{Materials and methods}

\section{Plant material and growth conditions}

Grains of barley (Hordeum vulgare L. cv. 'Golden Promise') were germinated in individual pots $(8 \times 8 \times 8 \mathrm{~cm})$ with a mixture of soil and vermiculite $(3: 1)$, at $22^{\circ} \mathrm{C}$ under a $16 / 8 \mathrm{~h}$ light/dark photoperiod, for $7 \mathrm{~d}$ in Sanyo MLR-350-H chambers. They were then subjected to drought stress by continuous water deprivation for $14 \mathrm{~d}$, following the method of Velasco-Arroyo et al. (2018). Control plants were grown under the same conditions but were watered to maintain soil moisture at $70 \%$, which Velasco-Arroyo et al. (2018) reported as optimal watering. At $14 \mathrm{~d}$ old, plants were transferred to bigger pots $(15 \mathrm{~cm}$ diameter $\times 13 \mathrm{~cm}$ high) and grown in a controlled greenhouse to allow grain production.

Knock-down lines for the HvPap-1 and HvPap-19 genes (KD Pap1 and KD Pap 19, respectively) were generated using artificial microRNA (amiRNA) technology according to Hensel et al. (2009). The generation and molecular characterization of the homozygous KD Pap1 plants (lines $1128,1130,1175$, and 1176) was previously reported by Diaz-Mendoza 
et al. (2016a). The amiRNA construct for the KD Pap19 lines was engineered from the $\mathrm{pNW} 55$ vector by replacing the 21 bases of the natural Osa-202 MIR528 miRNA to specifically silence the HvPap-19 gene (5'- TTTATTAACGGGCACATCCA-3'). Homozygous barley transgenic plants were obtained by double-haploid technology (Marthe et al., 2015). Molecular analysis (gene copy number, mRNA expression levels) of the KD Pap19 plants (lines 1770,1776,1779,1782) was performed as described by Diaz-Mendoza et al. (2016a). Grains of transgenic barley lines were germinated under the same conditions described above for the wild-type (WT) Golden Promise plants. At $7 \mathrm{~d}$ old, transgenic and WT plants were subjected to drought stress imposed by continuous water deprivation for $14 \mathrm{~d}$, with controls being watered on alternate days. Pots were placed over plastic plates to individualize watering. After the drought treatment, the oldest leaf (leaf 1) of each plant was harvested, frozen by plunging into liquid nitrogen, and stored at $-80^{\circ} \mathrm{C}$ until further analysis.

At $7 \mathrm{~d}$ old, leaves of plants of KD Pap1 (lines 1130, 1175), KD Pap19 (lines 1770, 1776), and the WT were infected with a strain of the fungus Magnaporthe oryzae expressing the pCAMB-Guy11 protein fused to GFP (green fluorescent protein; Leung et al., 1988), kindly provided by Dr Sesma (CBGP, UPM-INIA), following the method of Diaz-Mendoza et al. (2017). The plants were incubated at $25^{\circ} \mathrm{C}, 65 \%$ relative humidity (RH), under a $16 / 8 \mathrm{~h}$ light/dark photoperiod. Disease symptoms were monitored at different time points, and leaves were harvested after 3 and $7 \mathrm{~d}$ post-inoculation (dpi). Samples were frozen in liquid nitrogen and stored at $-80^{\circ} \mathrm{C}$ until analysis.

Independently, the same transgenic and WT lines were infested with 20 barley-adapted females per plant of the two-spotted spider mite Tetranychus urticae London strain (Acari: Tetranychidae), following the method of Santamaria et al. (2018b). After incubation at $25^{\circ} \mathrm{C}, 65 \% \mathrm{RH}$, under a 16/8 h light/dark photoperiod, leaf damage was monitored after $7 \mathrm{~d}$ of mite feeding. Samples were frozen in liquid nitrogen and stored at $-80^{\circ} \mathrm{C}$ until analysis.

\section{Real-time quantitative PCR analyses (RT-qPCR)}

Leaves of transgenic KD Pap19 and WT lines were used to analyse transgene copy number and to study gene expression levels. Copy number was calculated by the $2^{-\triangle \triangle C T}$ method according to Velasco-Arroyo et al. (2016). Leaves of KD Pap1, KD Pap19, and WT lines harvested after 14 $\mathrm{d}$ of drought or control conditions were used for RT-qPCR analysis, with four replicates. RNA extraction, cDNA synthesis, and RT-qPCR conditions were performed as described by Velasco-Arroyo et al. (2016). Quantification was standardized to the mRNA levels of barley cyclophitin ( $H v$ Cycl). Expression levels of the $M$. oryzae small subunit of ribosomal RNA (Mo28S-rRNA) and the T. urticae ribosomal protein 49 (TuRp 49) were also quantified by RT-qPCR according to Diaz-Mendoza et al. (2017). Fold-change values were expressed using the $2^{-\triangle \Delta C T}$ method (Livak and Schmittgen, 2001) relative to the normalized expression of the same genes in non-treated plants. Primer sequences are listed in Supplementary Table S1 at JXB online.

\section{Phenotypic assessment, and physiological and biochemical parameters}

Plant growth and stress symptoms were monitored over $14 \mathrm{~d}$ of drought, comparing controls versus treated WT and transgenic lines. Six replicates were sampled. The subsequent growth and development of plants were monitored weekly under controlled greenhouse conditions. Phenotypes and physiological parameters were monitored as the drought stress progressed, and were recorded at the same time of the day to avoid circadian effects. Plant above-ground biomass was determined at the end of each treatment as fresh weight, and then after drying in an oven at $70^{\circ} \mathrm{C}$ (dry weight). Soil water content was measured with a soil moisture sensor (SM150 Delta-T-Devices, Cambridge, UK). Stomatal conductance was determined using a leaf porometer (SC-1 Decagon-T, Pullman, USA). Quantum yield, an indicator of the efficiency of PSII, was evaluated using a portable fluorometer (FluorPen FP 100, Photon Systems Instruments, Drasov, Czech Republic). Photosynthetic pigments (total chlorophyll and carotenoids) were quantified from $100 \mathrm{mg}$ of leaves of transgenic and
WT plants after $14 \mathrm{~d}$ of drought and control conditions, following the method of Velasco-Arroyo et al. (2016). Pigment content was calculated using extinction coefficients and the equations of Lischtenthaler (1987).

\section{Protein quantification and western blot assays}

Total soluble proteins were extracted from water-stressed and non-stressed leaves of KD Pap1, KD Pap19, and WT lines as described by VelascoArroyo et al. (2016) and quantified on a microplate reader (Varioskan Flash, ThermoScientific) according to the method of Bradford (1976), using BSA as a standard. Four of replicates were sampled. Immunoblotting was performed as described by Velasco-Arroyo et al. (2016) with an antibody specific to the peptide NH2-CQEKKHFSIDAYQVNSDPHD$\mathrm{COOH}$ of the HvPap 19 protein. The optimal dilution for the primary antibody was as previously determined by Diaz-Mendoza et al., (2016a).

\section{Microscope analyses}

Leaves were cut from KD Pap1, KD Pap19, and WT barley plants grown with or without drought for $14 \mathrm{~d}$ and the cuticles were stained with Auramine $O$ according to Buda et al. (2009); 12 replicates were used. The specimens were mounted in a mixture of glycerol:PBS $(1: 1, \mathrm{v}: \mathrm{v})$ and observed using a Leica TCS SP8 confocal microscope under an Argon laser line of $458 \mathrm{~nm}$, with the emission of the dye collected in the range 490-560 nm. Stacks of $x y z$ and $x z y$ series were analysed using the programs LAS X and Fiji. For the $x z y$ series, $x z$ planes (perpendicular to the leaf surface) were taken along the $y$-axis. The distance between the first and the last $x z$ planes was $8.12 \mu \mathrm{m}$ for all $x z y$ series. Up to 50 individual measurements were taken along the cuticle of the maximum projections of the $x z y$ images using the program Fiji. The stomatal apertures were contoured and their area measured using Fiji.

For leaves infected with the fungus $M$. oryzae, the progress of the infection was monitored using a Leica TCS SP8 confocal microscope. The growth of the fungus was detected by the expression of green fluorescent protein (GFP, excitation $488 \mathrm{~nm}$, emission range 494-564 nm). Chlorophyll autofluorescence was used as a marker of cell viability (excitation $633 \mathrm{~nm}$, emission range $699-741 \mathrm{~nm}$ ). Random tacks of $21 x y z$ planes were collected at $40 \times$ magnification along the apical $2 \mathrm{~cm}$ of the leaves.

\section{Quantification of amino acids}

Samples were obtained from leaves of plants that had been water-stressed for $7 \mathrm{~d}$ and from controls of KD Pap1 (lines 1130, 1175), KD Pap19 (lines $1770,1776)$, and WT plants. Four replicates were used. Samples of $20 \mathrm{mg}$ were re-suspended in methanol, disrupted by three cycles of freeze/ thawing, and processed with a TissueLyser LT small bead mill (Qiagen). After centrifugation at $15700 \mathrm{rpm}$ for $20 \mathrm{~min}$, the supernatant was transferred to a new tube and dried in a SpeedVac. The metabolite extracts were re-suspended by $1 \mathrm{~min}$ vortex mixing in $0.1 \mathrm{~mol} \mathrm{ml}^{-1}$ of formic acid containing $0.2 \mathrm{mmol} \mathrm{l}^{-1}$ methionine sulfone (internal standard) and then centrifuged $(15700 \mathrm{rpm}, 15 \mathrm{~min})$. The clear solution was analysed by capillary electrophoresis-electrospray ionization-time-of-flight MS (CE-ESI-TOF MS). Every sample was prepared and analysed with three technical repeats.

Nineteen nitrogen metabolites (Ala, Arg, Asn Asp, betaine, Ile+Leu, Gln, Glu, His, Lys, Met, Phe, Pro, sarcosine, Ser, Trp, Tyr, and Val) were analysed by CE-ESI-TOF MS essentially as described by Moraes et al. (2011). The metabolites were previously identified in WT barley samples by comparison of their migration times and spectra with pure standards. A Capillary Electrophoresis System (7100, Agilent Technologies) coupled to a 6224 time-of-flight MS system (Agilent Technologies) was used. The separation occurred in a fused-silica capillary (Agilent; total length $100 \mathrm{~cm}$, i.d. $50 \mu \mathrm{m}$ ). Separation was under normal polarity with a background electrolyte containing $1.0 \mathrm{~mol} \mathrm{l}^{-1}$ of formic acid in $10 \%$ methanol $(\mathrm{v} / \mathrm{v})$ at $20{ }^{\circ} \mathrm{C}$. The sheath liquid $\left(6 \mu \mathrm{l} \mathrm{min}{ }^{-1}\right)$ was methanol/ water $(1 / 1, \mathrm{v} / \mathrm{v})$ containing $1.0 \mathrm{mmol} \mathrm{l}^{-1}$ formic acid with two reference masses to allow correction and thus higher accuracy in the MS. Samples were hydrodynamically injected at $50 \mathrm{mbar}$ for $35 \mathrm{~s}$ and stacked 
by injecting background electrolyte at $100 \mathrm{mbar}$ for $10 \mathrm{~s}$. The optimized MS parameters were: fragmentor $150 \mathrm{~V}$, skimmer $65 \mathrm{~V}$, octopole $750 \mathrm{~V}$, nebulizer pressure $10 \mathrm{psi}$, drying gas temperature $200^{\circ} \mathrm{C}$, and flow rate $10.01 \mathrm{~min}^{-1}$. The capillary voltage was $3500 \mathrm{~V}$. Data were acquired in positive Dual-ESI mode with a full scan from $\mathrm{m} / z 87$ to 1000 at a rate of $1.41 \mathrm{scan} \mathrm{s}^{-1}$. The resulting CE-MS data files were cleaned of background noise and unrelated ions by the Targeted Feature Extraction tool with Profinder software (B.08.00, Agilent). Linear regression coefficients were calculated for each compound and metabolites were quantified in the samples.

\section{Hormonal analysis}

Freeze-dried plant material was ground to fine p owder, weighed in 2- $\mathrm{ml}$ microtubes and spiked with $25 \mu \mathrm{l}$ of an internal standard mixture (containing $\mathrm{ABA}-d_{6}$, DHJA and ${ }^{13} \mathrm{C}_{6}-\mathrm{SA}$ ) to correct for analyte loses. Extraction was carried out in $1 \mathrm{ml}$ ultrapure water for $10 \mathrm{~min}$ in a ball mill at room temperature using $2-\mathrm{mm}$ glass beads. After extraction, the homogenates were centrifuged at $10000 \mathrm{rpm}$ for $10 \mathrm{~min}$ at $4{ }^{\circ} \mathrm{C}$ to remove debris. Supernatants were recovered, $\mathrm{pH}$ adjusted to 3.0 with $30 \%(\mathrm{v} / \mathrm{v})$ acetic acid, and partitioned twice against an equal volume of di-ethyl ether. The combined organic layers were evaporated under vacuum in a centrifuge concentrator (Jouan, Sant Germaine Cedex, France). The dry residues were subsequently reconstituted in $0.5 \mathrm{ml}$ of $10 \%(\mathrm{v} / \mathrm{v})$ aqueous methanol and the resulting solutions filtered through $0.20-\mu \mathrm{m}$ PTFE syringe membrane filters. Filtered extracts were analysed by tandem LC/MS in an Acquity SDS UPLC system (Waters Corp., USA) coupled to a TQS triple quadrupole mass spectrometer (Micromass Ltd., UK) through an electrospray ionization source. Separations were carried out on a C18 column (Gravity C18, $50 \times 2.1 \mathrm{~mm}, 1.8 \mu \mathrm{m}$ particle size, Macherey-Nagel, Germany) using a linear gradient of ultrapure methanol and water, both supplemented with acetic acid to a $0.1 \%(\mathrm{v} / \mathrm{v})$ concentration, at a constant flow rate of $0.3 \mathrm{ml} \mathrm{min}{ }^{-1}$. During analyses, the column was maintained at $40^{\circ} \mathrm{C}$ and the samples at $10^{\circ} \mathrm{C}$ to slow down degradation. Plant hormones were detected in negative electrospray mode by their specific precursor-to-product ion transitions (ABA, 263/153; JA, 209/59; SA, 137/93; SAGE, 299/93; OPDA, 291/165; JA-Ile, 322/130) and quantified using external calibration curves with standards of known amounts.

\section{Magnaporthe oryzae and Tetranychus urticae bioassays}

For plants infected with the fungus $M$. oryzae, disease symptoms were monitored at $3 \mathrm{~d}$ and $7 \mathrm{~d}$ post-inoculation (dpi). Lesions observed on infected leaves were scanned with a Scanjet 5590 Digital Flatbed Scanner HP). The area of damaged leaf surface was measured using the Assess 2.0: Image Analysis Software for Plant Disease Quantification. Six replicates per line were obtained and three independent experiments were performed.

For plants infested with the spider mite T. urticae, the area of damaged leaf surface was monitored after $7 \mathrm{~d}$ of mite feeding and quantified using Adobe Photoshop CS software, as described by Santamaría et al. (2017). The number of leaves per plant was counted before and after spider mite infestation. Six replicates per line were analysed and three independent experiments were performed.

\section{Statistical analysis}

Student's $t$-test was used to compare protease expression in control and drought conditions, and to compare the effects of drought on the cuticle thickness of every genotype. To compare the effects of the genotype under control or drought conditions, one-way ANOVA was used for HvPap-1 and HvPap-19 expression, cuticle thickness, stomatal pore area, metabolite contents, and physiological parameters, and two-way ANOVA was used to compare accumulation of hormones. For the bioassays, oneway ANOVA was used to compare foliar damage and pathogen/pest performance, and two-way ANOVA was used to compare the number of leaves. ANOVA analyses were followed by the Student-Newman-Keuls multiple comparison tests.

\section{Results}

\section{Response of barley C1A CysProt genes to drought}

The expression profiles of the 41 C1A CysProt genes in barley leaves after $14 \mathrm{~d}$ of drought were assessed by RT-qPCR assays and were expressed as mRNA levels normalized to the constitutive active cyclophilin gene. The results showed that two $\mathrm{B}$-like, one F-like, the only H-like, and eight out of the 34 barley L-like cathepsin genes were expressed in leaves in control and/or drought conditions (Fig. 1). However, only four protease gene members were significantly induced in stressed leaves in comparison to control plants, namely HvPap-8 (L-like), HvPap12 (H-like), HvPap1 (F-like), and HvPap-19 (B-like). To obtain further insights into the role of barley CysProt during drought stress, HvPap-1 and HvPap-19 knock-down plants were used. In addition to the KD Pap1 lines $(1128,1130,1175$, and 1176) previously characterized by Diaz-Mendoza et al. (2016a), transgenic plants for the HvPap-19 gene (KD Pap19 lines) were generated using the same artificial amiRNA approach via Agrobacterium-mediated transformation. Homozygous KD Pap19 lines were selected for further characterization based on transgene copy number, and transcript and protein contents. Following these criteria, the KD Pap19 lines 1170,1176, 1179, and 1182 were selected (Supplementary Fig. S1). Lines 1170 and 1176 contained a unique copy of the transgene whereas lines 1179 and 1182 had two gene insertions, as estimated by RT-qPCR assays and the $2^{-\triangle \triangle C T}$ method. The mRNA expression levels in all of them were reduced compared with the WT control. Immunoblot assays using a specific antibody against a peptide of HvPap-19 (previously checked to avoid cross-reactivity; Diaz-Mendoza et al., 2016a) showed a reduction in the accumulation of the protein content in comparison with the WT (Supplementary Fig. S1). However, neither mRNA nor protein content was completely knocked-out, indicating the knock-down character of these lines.

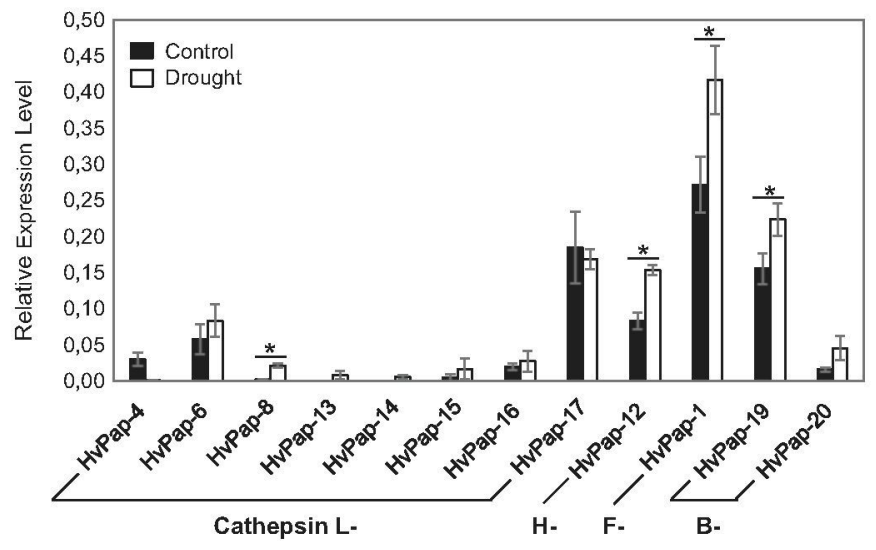

Fig. 1. Expression of CysProt genes in barley leaves after $14 \mathrm{~d}$ of drought or standard watering (control). All 41 C1A CysProt genes in barley were assessed but only those that were expressed under drought and/or control conditions are shown. Data were determined by RT-qPCR and are expressed as relative mRNA levels normalized to that of barley cyclophilin. The data are means $( \pm \mathrm{SE}$ ) of three independent biological replicates. Significant differences between means were determined using unpaired t-tests: ${ }^{*} P<0.05$. 
Since HvPap-1 and HvPap-19 mRNAs were up-regulated after drought stress in WT plants, the expression patterns for both genes in the knock-down lines were also examined after drought. In comparison to WT plants, a significant reduction of both HvPap-1 and HvPap-19 expression was observed not only in the corresponding $\mathrm{KD}$ line but also in the line for the other transgene, either grown under watered or droughtstressed conditions (Supplementary Fig. S2). However, the mRNA levels of HvPap-1 in the drought-stressed KD Pap19 lines were higher than that those in the KD Pap1 lines. In contrast, the mRNA levels of HvPap-19 were similar in the KD Pap 1 and KD Pap 19 lines both before and after drought stress.

\section{Barley HvPap-1 and HvPap-19 knock-down lines show phenotypic structural alterations}

The phenotypes of the three barley genotypes were compared with controls after $14 \mathrm{~d}$ of drought. Watered WT and KD Pap19 plants looked more robust and tended to be taller than KD Pap1 plants (Supplementary Fig. S3). Under water stress, WT plants seemed to be more affected with less leaf turgor, while the leaves of both the KD lines stayed upright. In addition, leaf growth of the KD Pap19 lines tended to be greater than that of KD Pap 1.

The full growth cycle of the KD Pap1 and KD Pap19 lines was compared to that of WT plants, and no relevant phenotypic alterations were observed during the first 8 weeks of development (Supplementary Fig. S4). By the end of their lifespan, a slight delay in natural senescence was observed in the KD Pap1 lines compared with the non-transformed plants. A delay in senescence in KD Pap1 lines has been previously reported by Diaz-Mendoza et al. (2016a). In contrast, the KD Pap 19 phenotypes were quite similar to the WT plants through the complete life cycle.

Interestingly, leaves from transgenic and WT plants showed apparent differences in surface texture and hardness. Further examination of leaf cuticle structure and thickness were therefore conducted by confocal microscopy following staining. The thickness of the cuticle on the adaxial side of the leaf was significantly increased in the transgenic KD Pap1 lines relative to the WT (Fig. 2). Under drought, leaf cuticles become thicker in all three barley genotypes, but the KD Pap1 lines presented significantly thicker cuticles than KD Pap19 and WT plants. Moreover, the outer shape of epidermal cells of drought-stressed leaves looked more irregular than the controls (Fig. 2). Staining with Auramine $\mathrm{O}$ also showed changes in the stomata, and although the mean number per unit leaf surface area was not altered either among lines or between stressed versus non-stressed leaves (data not shown), some modifications in position, size, and aperture were observed. Generally, the stomata tended to be located in a lower position in relation to the general epidermal cells, particularly in transgenic leaves after drought (Fig. 2). The stomatal pore area of watered-WT leaves was larger than in the transgenic leaves under the same conditions. While leaves of the WT and KD Pap1 plants maintained their stomata open under watered conditions, in the KD Pap19 lines the stomata were almost closed (Fig. 3). Under drought stress, the stomatal pore area

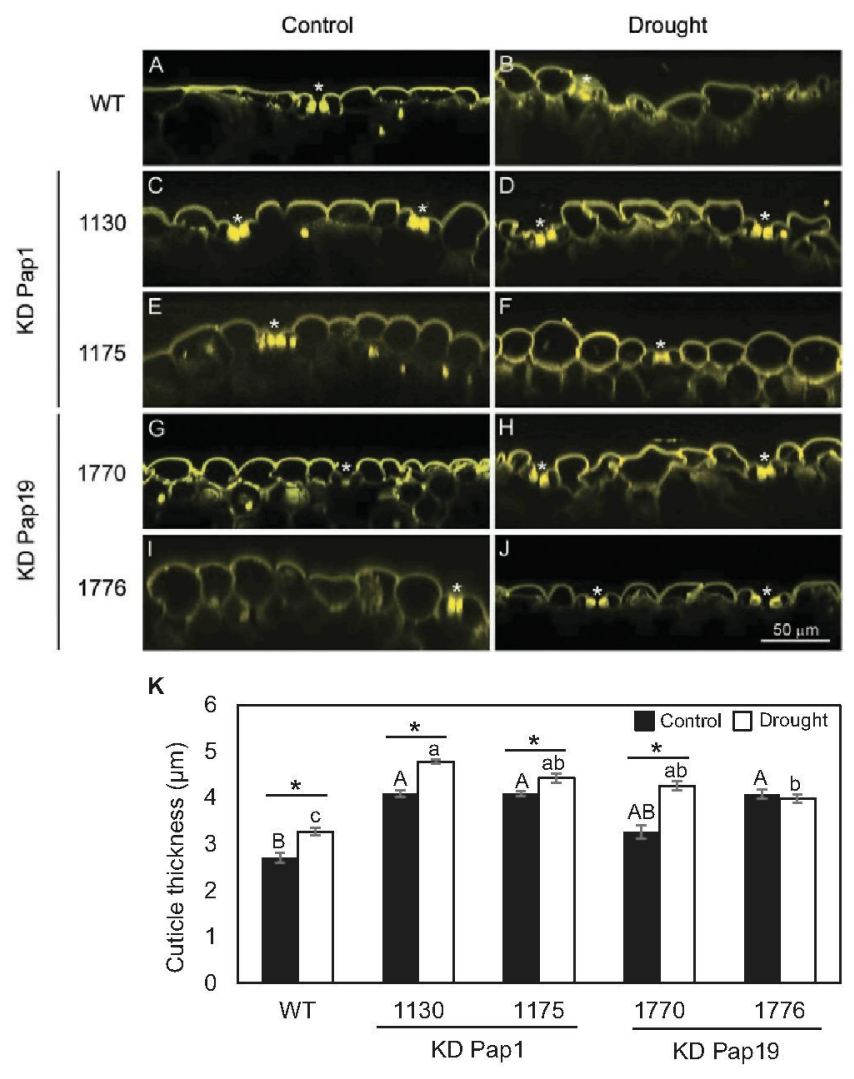

Fig. 2. Cuticles of barley leaf epidermis stained with Auramine $O(A-J)$. Stacks of $x z$ planes across a fixed width $(8.12 \mu \mathrm{m})$ along the $y$-axis were collected using a confocal microscope. The leaves are from drought and control treatments for KD Pap1 (lines 1130, 1175), KD Pap19 (lines 1770,1176 ) and wild-type (WT) plants. Asterisks indicate the positions of stomata in the epidermal layers. (K) Quantification of cuticle thickness was performed by taking up to 50 measurements per image using the program Fiji. Data are means ( \pm SE) of measurements from three independent biological replicates. Different letters indicate significant differences as determined using one-way ANOVA followed by a Student-NewmanKeuls test $(P<0.05)$. Significant differences between pairs of means were determined using unpaired $t$-tests: ${ }^{*} P<0.05$.

of the KD Pap19 lines was larger than that of KD Pap1 and much larger than in WT plants, which correlated with the stomatal aperture (Fig. 3).

To place the changes in cuticle/stomata features in the context of the drought stress imposed, some physiological parameters associated with the stress were analysed. Soil water content was severely reduced after 14 $\mathrm{d}$ of drought treatment independent of the barley genotype (Supplementary Fig. S5A). Dry and fresh weights did not show any differences among the genotypes when the plants were grown under a drought regime (Supplementary Fig. S5B-C). Reductions in other markers of drought stress, such as total chlorophyll and carotenoid contents, were detected in stressed versus control plants but no relevant differences were found between transgenic and WT plants (Supplementary Fig. S5D-F). In contrast, significantly higher quantum efficiency of PSII and greater total protein contents were found in drought-stressed KD Pap1 and KD Pap 19 lines in comparison to the WT, whereas no differences were observed under watered conditions (Fig. 4). 
Metabolite changes associated with drought stress in HvPap-1 and HvPap-19 knock-down lines and WT plants

To determine whether the differential levels of mRNA detected in the leaves was related to differences in the free amino acid composition, a metabolomics analysis was performed by comparing the amount of free amino acids and related compounds

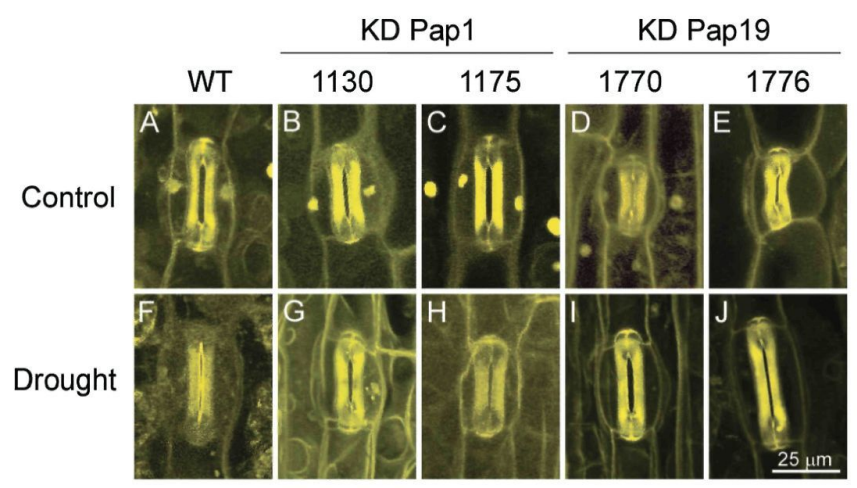

K

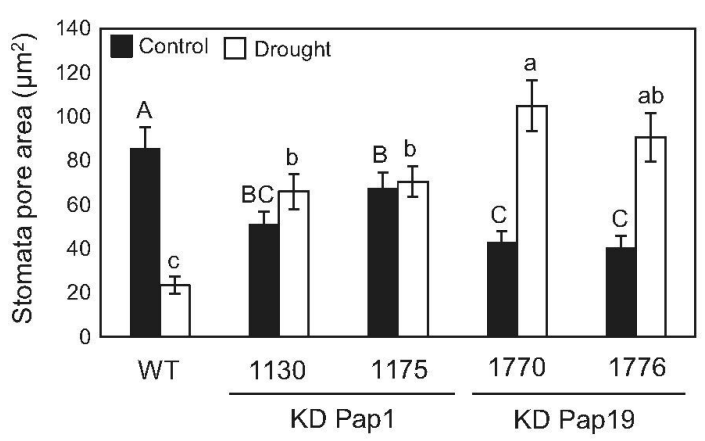

Fig. 3. Stomata of barley leaf epidermis stained with Auramine $O$, and stacks of $x y z$ series (parallel to the leaf surface) collected using a confocal microscope (A-J). The leaves are from drought and control treatments for KD Pap1 (lines 1130, 1175), KD Pap19 (lines 1770, 1176) and wildtype (WT) plants. (K) The stomatal areas were manually contoured and measured using the program Fiji. Data are means $( \pm$ SE) of at least 12 replicates from three independent biological experiments. Different letters indicate significant differences as determined using one-way ANOVA followed by Student-Newman-Keuls tests $(P<0.05)$. in transgenic and WT leaves under drought and watering regimes. Significant differences between the concentration of many amino acids were found between the knock-down lines and the WT, both in control and in drought conditions (Supplementary Table S2). In the KD Pap1 lines most compounds had significantly higher or lower concentrations than in WT plants. In spite of these quantitative differences, the contribution of each compound to the total set showed quite similar trends in all the lines, even in the more divergent KD Pap1 1130 line (Fig. 5). The amino acids Glu, Gln, Asp, and Asn, and the compounds betaine and sarcosine were the most abundant metabolites in watered conditions. The contribution to the total pool of metabolites decreased for these compounds in all lines after drought treatment, with the exception of betaine, which increased. A strong increase of Pro in the total pool was found under drought, together with minor increases for several hydrophobic amino acids such as Leu+Ile, Val, Tyr, and Trp.

\section{Differential accumulation of hormones among KD and WT lines in response to drought}

The content of various hormones was determined in leaves grown under drought or watered conditions in order to determine whether the responses to drought stress were regulated similarly between the three barley genotypes (Fig. 6, Supplementary Table 3). The results showed that levels of OPDA, the precursor of the JA pathway, were elevated in the leaves of the KD Pap1 lines grown under control conditions, but in response to drought they fell to levels similar to the other two genotypes (Fig. 6A). On the other hand, JA and its bioactive form JA-Ile accumulated dramatically in response to drought in KD Pap1 and WT leaves. Whilst the results for JA and JA-Ile were inconsistent in the two KD Pap19 lines under control conditions, their levels were significantly lower than those of the WT and KD Pap1 after drought stress (Fig. 6B, C). As expected, the ABA concentration was greatly increased under water deficit in all the leaf samples, but the amounts were significantly higher in the two KD lines under stress than in WT plants (Fig. 6D). Finally, the amount of SA did not differ either among the lines or between the treatments, and
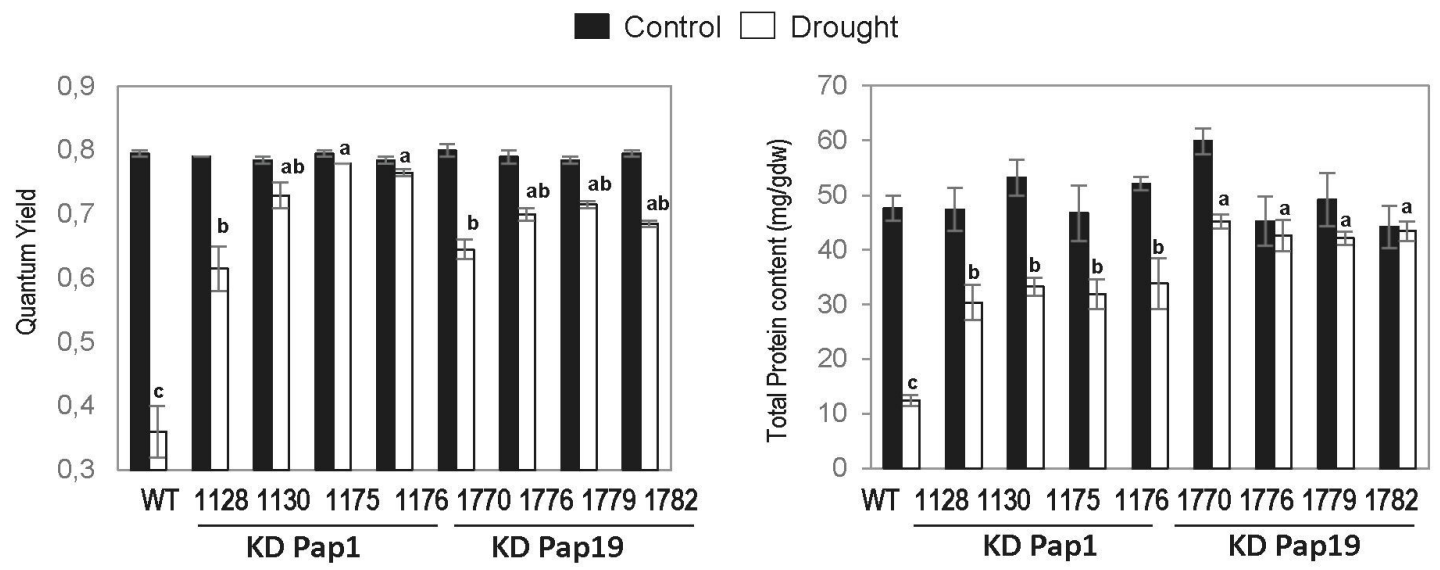

Fig. 4. Physiological parameters of barley KD Pap1, KD Pap19, and wild-type (WT) plants after 14 d of drought or control treatments. (A) Quantum yield, and $(B)$ protein content. Data are means $( \pm \mathrm{SE})$ of at least six replicates from three independent biological experiments. Different letters indicate significant differences as determined using one-way ANOVA followed by Student-Newman-Keuls tests $(P<0.05)$. 


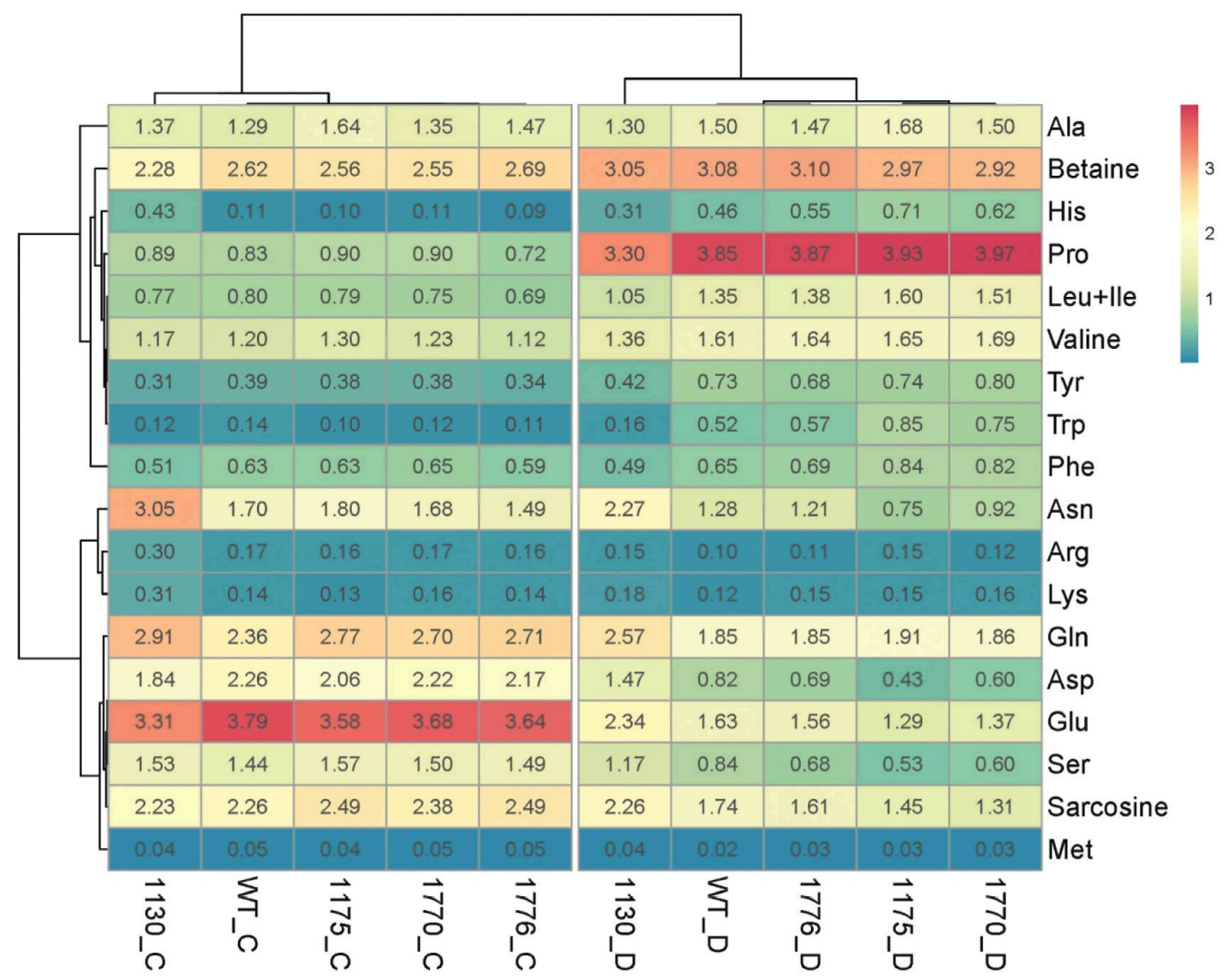

Fig. 5. Heatmap of the composition in free amino acids and related compounds before and after $14 \mathrm{~d}$ of drought (D) in barley leaves of KD Pap1 (lines 1130 and 1175), KD Pap1 9 (lines 1770 and 1776), and wild-type (WT) plants compared with well-watered controls (C). The colour coding shows the level of abundance quantified as the proportion (\% of total) of each metabolite in the different samples. The original values have been In $(x+1)$-transformed. No scaling is applied to the rows. Both rows and columns are clustered using correlation distance and average linkage.

its glycosylated form, the salicylic acid glucosyl ester (SAGE), only showed significant differences in the KD Pap19 lines, with higher levels after drought treatment (Fig. 6E, F).

\section{HvPap-1 and HvPap-19 knock-down lines differentially respond to biotic stresses}

Since the leaf cuticles and stomata were differentially altered in the KD Pap1 and KD Pap19 lines relative to the WT plants, the effects of these structural changes on defense responses to pathogens and pests examined after $M$. ozyzae infection and T. uticae feeding, respectively. Initially, the $M$. oryzae fungal infection produced spots with necrotic borders that could enlarge and coalesce to colonize the entire leaf (Fig. 7). The highest level of injury was detected in leaves from the KD Pap19 lines, particularly in the oldest leaf (L1) and in the apex of leaf 2 (L2), with the damaged area being very high at $7 \mathrm{~d}$ post-inoculation (dpi). In contrast, the damaged area in the KD Pap1 lines was significantly lower, whilst WT leaves showed intermediate levels of damage at both $3 \mathrm{dpi}$ and $7 \mathrm{dpi}$ (Fig.7). To enable examination of the cellular events taking place during the early stages of the barley-fungus interaction, fluorescent GFP-labelled Magnaporthe isolates were used to inoculate the plants. Confocal fluorescence microscopy revealed that invasive hyphae were highly developed at 3 dpi in the KD Pap19 lines, which inversely correlated with leaf autofluorescence due to the chlorophyll, a marker of cell viability (Fig. 8D, E). This result was consistent with differences in leaf damage. An intermediate balance between fungus-GFP and plant chlorophyll fluorescence was detected in infected WT leaves while autofluorescence was more prominent in infected KD Pap1 lines (Fig. 8A-C).

To study the impact of the HvPap-1 and HvPap-19 genes on the performance of $M$. oryzae, RT-qPCR assays were carried out to measure the mRNA levels corresponding to the small subunit of ribosomal RNA (Mo28S-rRNA). The results showed a significantly higher quantity of fungal mRNA in leaves of KD Pap19 compared with KD Pap1 and WT plants at 3 dpi (Supplementary Fig. S6). At 7 dpi, the low levels of fungal mRNA found in the KD Pap19 lines was due to the death of most leaf tissue in these lines.

Transgenic and WT plants were also subjected to pest attack by mites of $T$. urticae, and the effects were observed after $7 \mathrm{~d}$ of feeding. Small chlorotic spots appeared due to the penetration of mite stylets and subsequent plant cell-sucking (Fig. 9D); greater levels of injury were observed following longer infestation times (data not shown). Infested KD Pap1 lines showed less leaf damage than infested WT plants, and the number of leaves per plant was not affected in comparison with noninfested plants (Fig. 9A, B). In contrast, the impact of mites on the KD Pap19 lines was severe with the leaf injury being much higher than in infested WT plants and the number of leaves per plant was reduced. The performance of T. urticae was monitored by quantifying the mRNA levels of ribosomal 

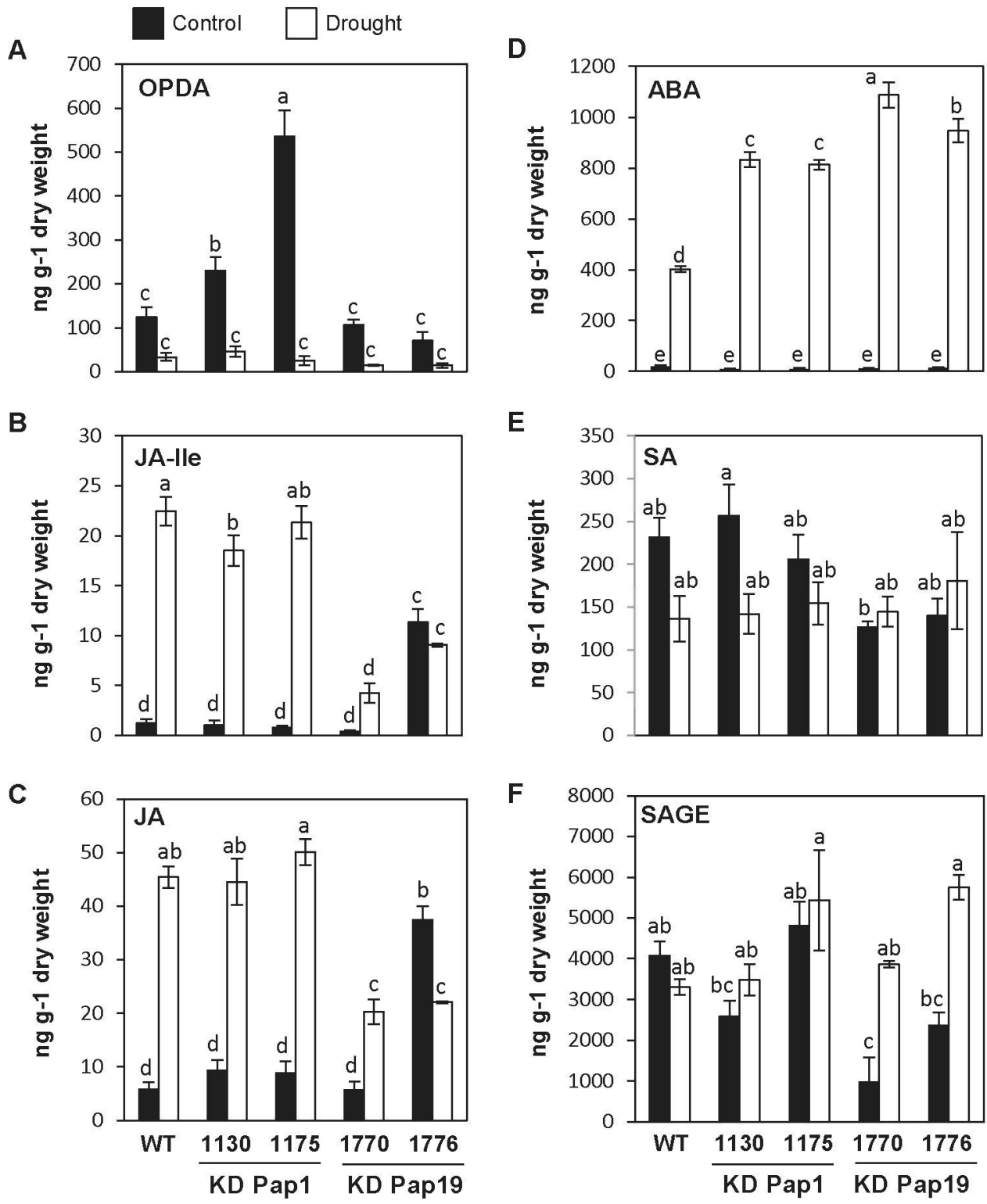

Fig. 6. Quantification of hormones in barley KD Pap1 (lines 1130, 1175), KD Pap19 (lines 1770, 1176), and wild-type (WT) plants after 14 d of drought or control treatments. (A) OPDA, 12-oxo-phytodienoic acid; (B) JA, jasmonic acid; (C) JA-lle: JA-isoleucine; (D) ABA, abscisic acid; SA, (E) salicylic acid; (F) SAGE, salicylic acid glucosyl ester. Data are means $( \pm \mathrm{SE}$ ) from three independent biological replicates. Different letters indicate significant differences as determined by two-way ANOVA followed by Student-Newman-Keuls tests $(P<0.05)$.

protein 49 (TuRP49). A significant increase in TuRP49 gene expression was found when mites fed on the KD Pap19 lines (Fig. 9C), which correlated with the greater leaf damage. Low TuRP49 mRNA levels in KD Pap1 were associated with the low leaf damage that was observed. Intermediate levels of mite gene expression and leaf damage were observed in infested WT plants when compared to the KD lines.

\section{Discussion}

Plant survival under drought stress, which is of particular significance in the current context of global warming, depends on the ability to detect the stress and make adjustments to mitigate the impact. Plants induce molecular mechanisms, modify physiological processes, and adapt their growth patterns to optimize their use of water under drought stress (Osakabe et al., 2014). Altered expression of members of the cysteineprotease (CysProt) family is often linked to these changes since turnover with rapid degradation and mobilization of proteins is enhanced under stress conditions (Kunert et al., 2015; VelascoArroyo et al., 2016). Our examination of expression levels of the 41 barley C1A CysProt genes after $14 \mathrm{~d}$ of water deficit revealed that four of of them, HvPap-1, HvPap-8,HvPap-12, and HvPap-19, were induced (Fig. 1) suggesting a putative role in proteolytic processes specifically triggered by drought stress.

Most efforts to understand the role of CysProts under a drought conditions have been made by overexpressing genes ectopically (Chen et al., 2010, 2013; Zang et al., 2010). In our study, for the first time CysProt knock-down lines were generated in order to examine plant responses to drought. The transgenic HvPap-1 and HvPap-19 lines showed differences in some biochemical and physiological parameters associated 


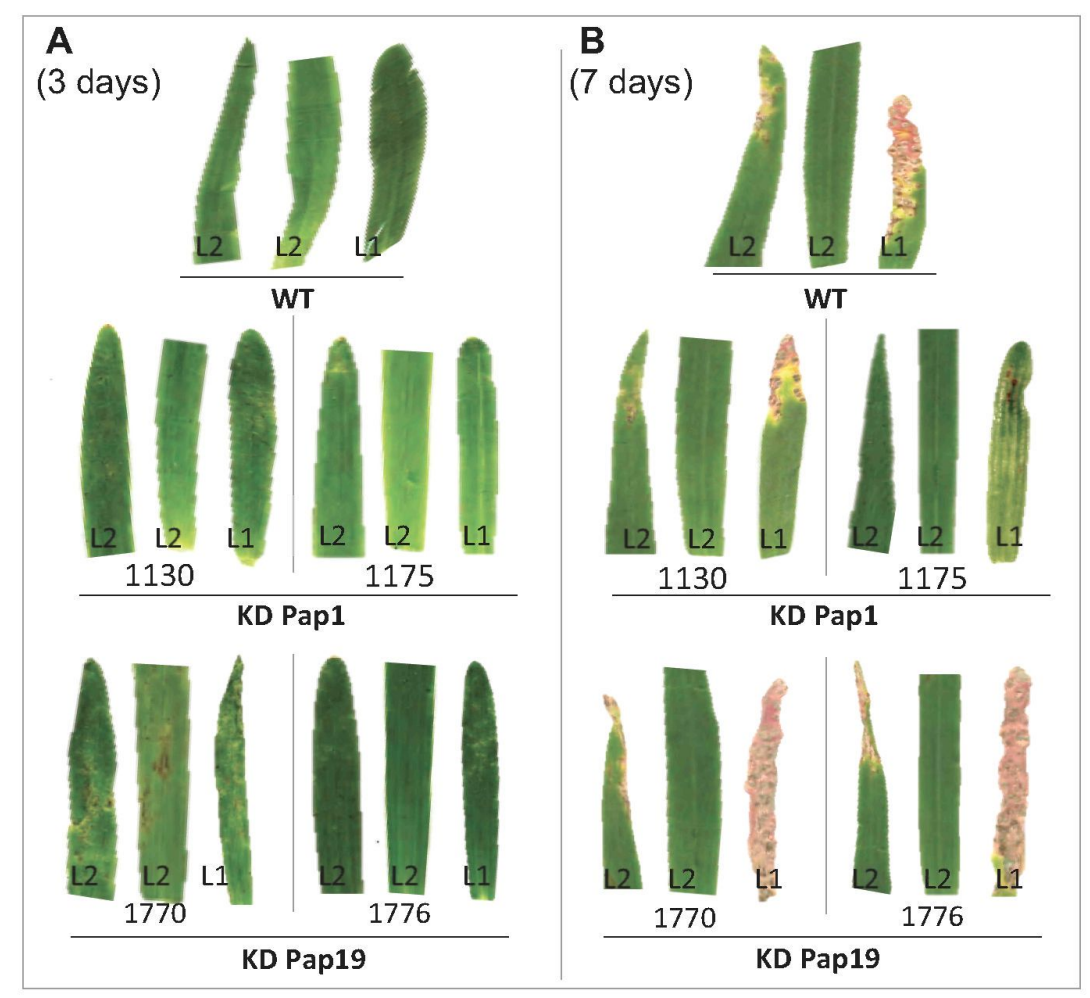

C
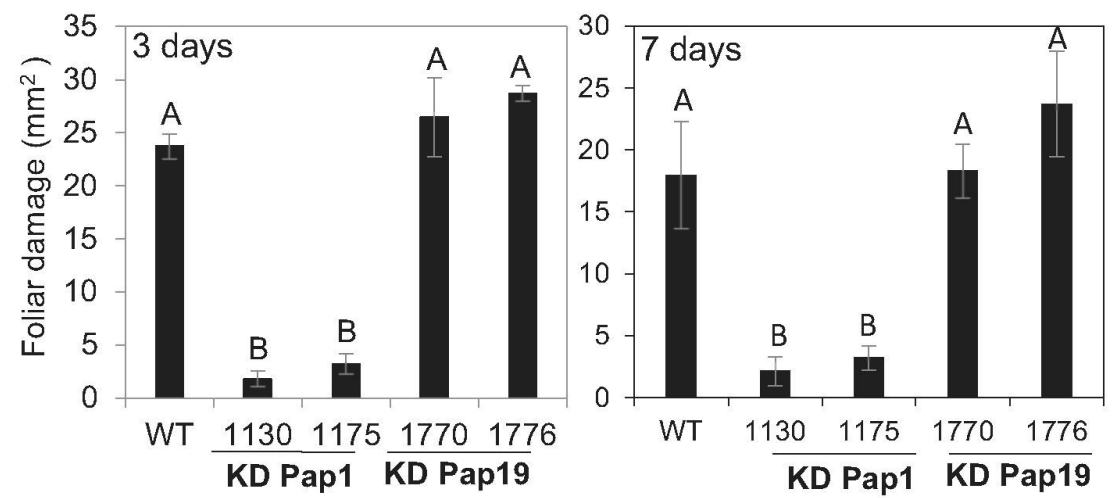

Fig. 7. Plant phenotypes and leaf damage after M. oryzae infection of leaves of barley KD Pap1 (lines 1130, 1175), KD Pap19 (lines 1770, 1176), and wild-type (WT) plants. Plant phenotypes after (A) $3 \mathrm{~d}$ and (B) $7 \mathrm{~d}$ of infection. (C) Quantification of leaf damage measured as mm ${ }^{2}$ of injured foliar area in all leaves of each plant after $3 \mathrm{~d}$ and $7 \mathrm{~d}$ of infection. Data are means $( \pm$ SE) from four independent plants. Different letters indicate significant differences as determined by one-way ANOVA followed by Student-Newman-Keuls tests $(P<0.05)$.

with drought stress in comparison to WT plants (Fig. 4, Supplementary Fig. S5). While drought caused a significant decline in the maximum quantum yield of PSII in WT plants, the efficiency of PSII was virtually unaltered in the knock-down lines. Likewise, the total amount of proteins, an important parameter associated with drought, was greatly reduced in stressed leaves of the WT but only slightly decreased in the two transgenic lines. These findings demonstrated the participation of the two CysProts in the plant adaptation to drought stress. The patterns of proteolytic activity in the knock-down lines did no show significant differences compared to the WT (data not shown), probably due to compensating effects as a consequence of the functional redundancy of CysProts that has been reported previously (Velasco-Arroyo et al., 2016, 2018). Thus, although the contribution of each metabolite was quite similar in all lines both before and after drought (Fig. 5), it induced greater increases in many free amino acids in the KD lines than in the WT, consistent with proteolytic compensation effects. Increases in proline and betaine, two osmolytes with roles in the protection of subcellular structures in stressed plants, are known to be related to enhanced tolerance to drought (Ashraf and Foolad, 2007), and thus the increases would protect the plants from dehydration.

As previously reported (Velasco-Arroyo et al., 2016), the KD Pap1 plants presented a slight delay in senescence compared to WT plants (Supplementary Fig. S4). The growth behaviour of the KD Pap19 plants across the whole life cycle did not show any important modifications. So, adjustments in growth seemed to be mainly dependent on the CysProt gene. There are examples of plants expressing CysProt transgenes 

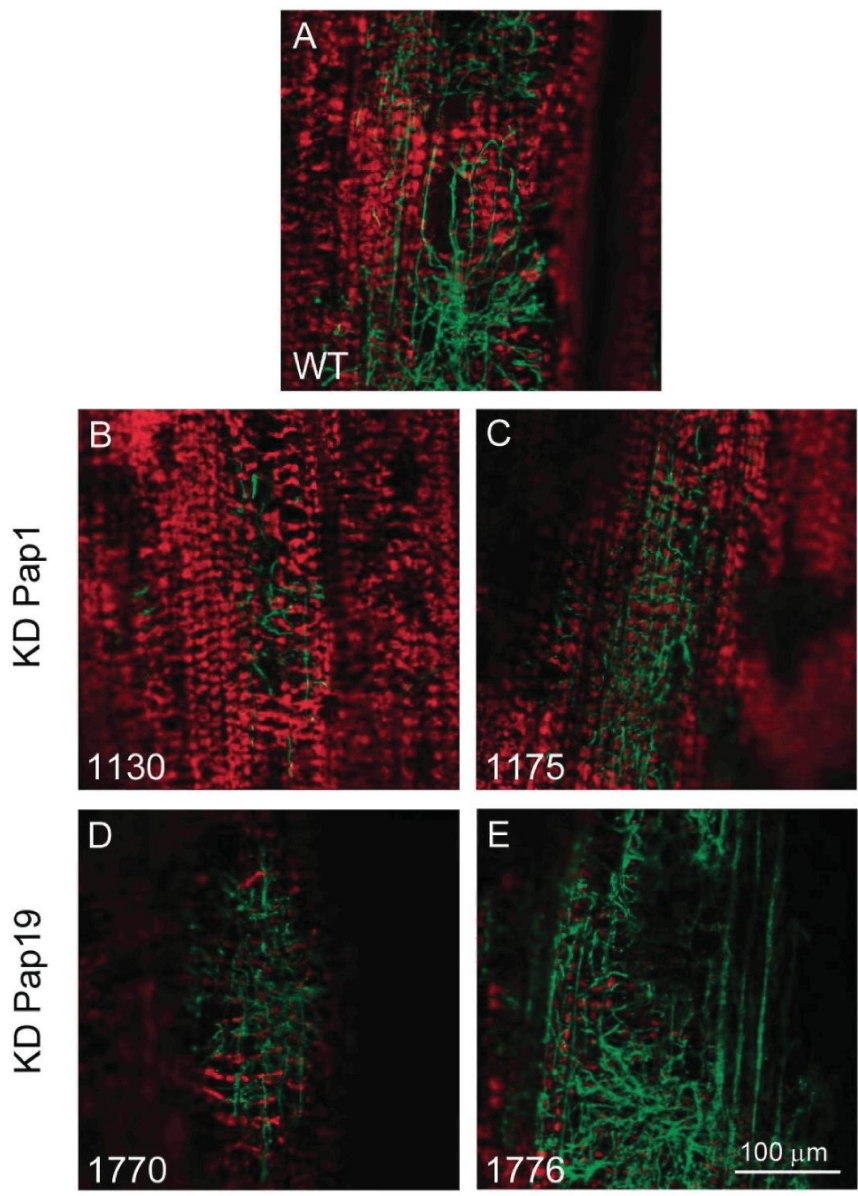

Fig. 8. Confocal images of leaves of barley KD Pap1 (lines 1130, 1175), KD Pap19 (lines 1770, 1176), and wild-type (WT) plants infected with $M$. oryzae expressing the protein pCAMB-Guy 11 fused to green fluorescent protein. The images were taken at $3 \mathrm{~d}$ post-inoculation. The green fluorescence of the hyphae and chlorophyll autofluorescence, as a marker of tissue damage, were detected using a confocal microscope. Series of $21 x y z$ images were collected from random areas along the apical $2-\mathrm{cm}$ of the leaves. Maximum projections are shown.

with different growth patterns. Transgenic Arabidopsis plants constitutively overexpressing PSPC2 and SPCP3 CysProt from sweet potato present earlier floral transition from vegetative to reproductive growth, in addition to alterations in seed germination in comparison to WT plants (Chen et al., 2010, 2013). On the other hand, HvPap-1 overexpressing barley lines exhibit a similar growth phenotype to that observed for WT plants (Velasco-Arroyo et al., 2016). Interestingly, the delayedsenescence- phenotype of the KD Pap1 lines was accompanied by the presence of thicker leaf cuticles than WT plants, and alterations in the stomatal position, size and aperture (Figs 2,3). These unexpected structural modifications, which were even more notably after drought, clearly supported the longer life cycle since cuticles act as physical barriers that protect plants and help their survival (Bi et al., 2017; Xue et al., 2017). It is difficult to find the link between the low expression of a CysProt gene in the KD lines and the alterations in the structure of the leaf cuticle. CysProts participate in multiple physiological processes either directly involved in degrading proteins or sometimes in degradation of pre-proteins to generate active forms, such as enzymes (Grudkowska and Zagdańska, 2004;
Martínez et al., 2012). This led us to hypothesize that the different enzymes required for the synthesis of the cuticular wax components and cutin matrix could somehow be the target of the CysProts. Cutin and wax are synthesized in the ER and exported via ATP-binding cassette $(\mathrm{ABC})$ transporters across the plasma membrane to the polysaccharide cell wall (Yeats and Rose, 2013; Xue et al., 2017). Barley CysProts and cystatins have been localized in the ER and Golgi apparatus (Martinez et al., 2009, 2012); thus, an imbalance in the enzymes in the KD lines could affect the structure and/or composition of the cuticle. Alternatively, pleitropic effects associated with the silencing of the CysProt genes due to a parallel reprogramming of other genes could have mediated the leaf structural changes that were observed.

Among the physical adaptations to drought stress, an efficient stomatal structure is essential for an appropriate and rapid response. Usually, plant growth is impaired under water deficit due to a decrease in stomatal opening that limits $\mathrm{CO}_{2}$ uptake and has negative consequences on photosynthesis (Osakabe et al.,2014).Although stomata tend to be closed under drought, leaves of KD Pap1 and, especially, KD Pap19 plants kept their stomata open (Fig. 3). This could be an adaptation to compensate for the reduction in the transpiration process due to the presence of their thicker cuticles (Kosma et al., 2009; Bi et al., 2017). In addition, drought stress led to an increase in accumulation of ABA (Fig. 6), which is the main driver of stomatal closure to diminish gas exchange and transpiration, and to reduce water loss (Osakabe et al., 2014; Sah et al., 2016). The high ABA concentrations detected in leaves of drought-stressed plants, and particularly in both the KD lines, is in line with its role as a modulator to avoid water losing. Since these high levels did not result in stomatal closure, the $\mathrm{KD}$ lines might be deficient in their ability to sense ABA. In parallel, the accumulation of JA and its active form JA-Ile in water-stressed KD Pap1 and WT plants was in agreement with previous reports in other plant species grown under drought (Mahouachi et al., 2007; de Ollas et al., 2015). Recent reports have demonstrated that JA regulates a subset of plant responses to drought by modulating ABA biosynthesis and accumulation (de Ollas and Dodd, 2016; De Ollas et al., 2018). Curiously, levels JA and JA-Ile were significantly lower in leaves of water-stressed KD Pap19 lines than in KD Pap1 and WT plants. This hormone is potentially required for the maximum sensitivity of stomata to drying soil (De Ollas et al., 2018), and the low levels of JA and JA-Ile could have been correlated with the stomatal apertures observed in these plants even under drought stress.

Cuticles are not only barriers to desiccation but also form protective structures to biotic stress. On this basis, we decided to challenge the different genotypes with the fungal pathogen $M$. oryzae and the phytophagous pest T. urticae. As expected, KD Pap1 plants, whose leaves presented thicker cuticles, showed less damaged after $7 \mathrm{~d}$ of fungal infection or mite feeding than WT plants (Figs 7-9). In contrast, the foliar damage detected on KD Pap19 plants after pathogen and pest attack was higher than in WT plants. The leaf damage correlated with the amount of fungus or mite mRNAs determined in each case. The enhanced defense shown by the KD Pap1 lines against $T$. urticae attack was not in line with previous data from 
A

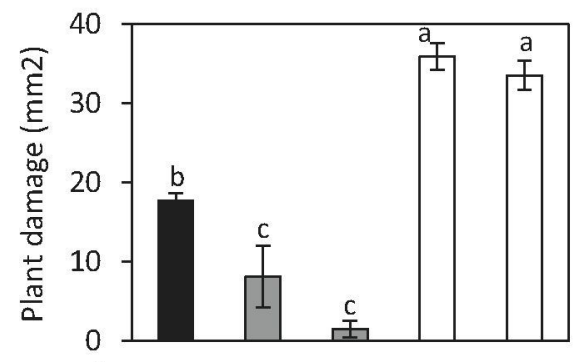

B

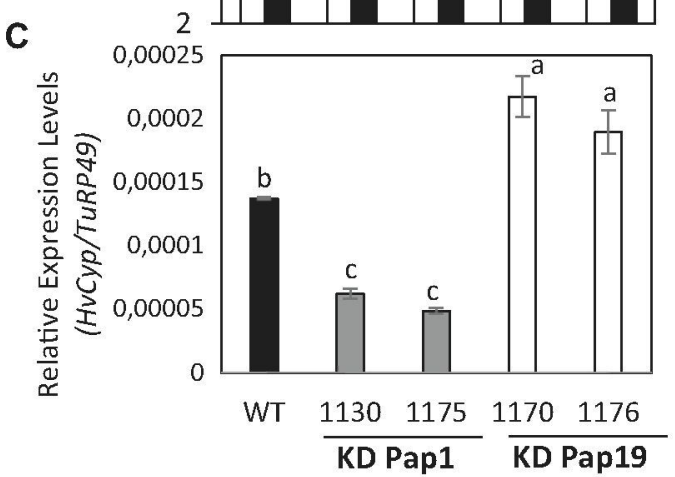

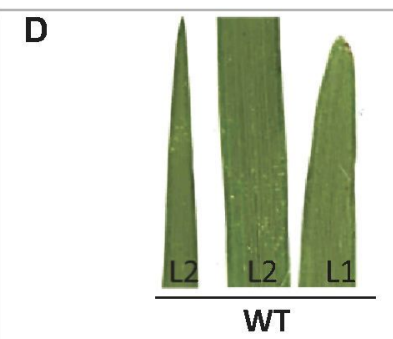
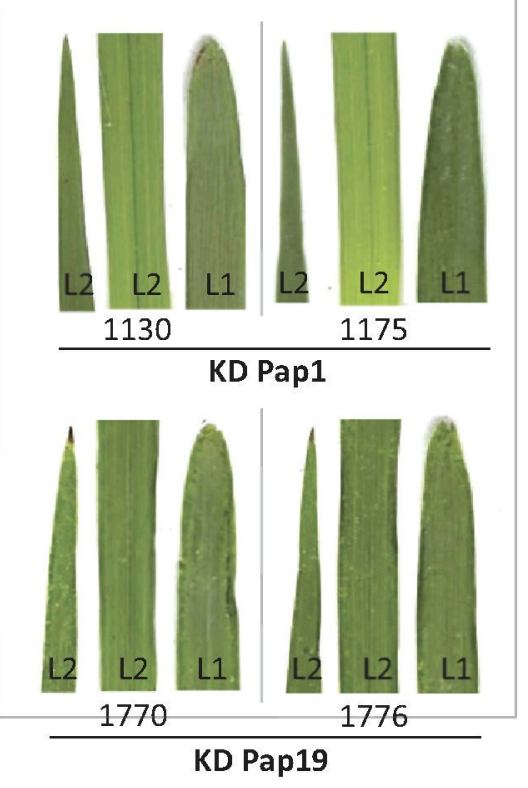

Fig. 9. Plant phenotypes and mite performance after $7 \mathrm{~d}$ of infestation with T. urticae for barley KD Pap1 (lines 1130,1175 ), KD Pap19 (lines 1770 ,

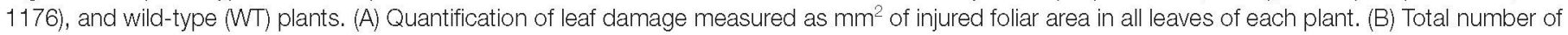
leaves per plant of mite-infested and non-infested plants. (C) Mite performance as quantified by the relative expression levels of the $T$. urticae ribosomal

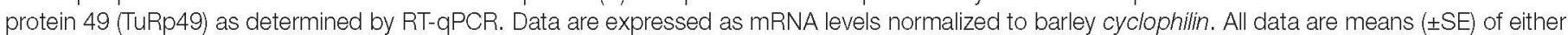
$(A, B)$ four plants or (C) three independent biological replicates. Different letters indicate significant differences as determined by either ( $\mathrm{A}$, one-way or

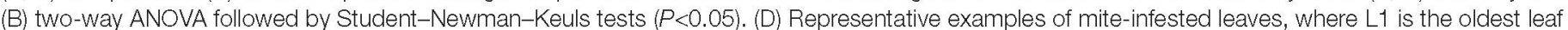
and $L 2$ is the next leaf on the plant.

bioassays performed by Diaz-Mendoza et al. (2017). It is likely that the different plant response was due to differences in the mite population used to infest the plants: while Diaz-Mendoza et al. (2017) employed adult mites that were adapted to barley, here the infestation was performed with a barley-adapted synchronized population of female mites. Only females at the same stage of development were used for the feeding bioassays. The different susceptibility of KD Pap1 and KD Pap19 plants to biotic stresses also probably did not only depend on the cuticle thickness. For example, hormones and regulators actively participate in the responses triggered by biotic stresses and act as important cues for producing greater resistance. Previous reports examining effects of pathogens or insects on leaves with either overexpression or silencing of CysProt have shown that the plant responses and the impact on the pathogen/pest are specific for each plant-organism interaction (Pechan et al., 2002; Gilroy et al., 2007; Shindo et al., 2012; Höwing et al., 2014).

We can conclude that barley HvPap-1 and HvPap-19, which encode cathepsin F- and B-like CysProt, respectively, are functional genes involved in drought stress processes. Their absence, even partial, alters phenotypic traits and unexpectedly produces leaf structural alterations that may confer differential susceptibility to abiotic and biotic stresses.

\section{Supplementary data}

Supplementary data are available at $J X B$ online.

Fig. S1. Characterization and selection of transgenic lines.

Fig. S2. mRNA content in leaves of the different barley genotypes.

Fig. S3. Barley phenotypes after drought treatment.

Fig. S4. Phenotype of barley plants at 4-12 weeks of development.

Fig. S5. Physiological parameters in the different barley genotypes.

Fig. S6. Expression of a $M$. oryzae constitutive gene after infecting different barley genotypes.

Table S1. List of primers used in this study.

Table S2. Amino acids and related compounds in the leaves of the different barley genotypes.

Table S3. Hormone contents in the leaves of the different barley genotypes. 


\section{Acknowledgments}

This work was supported by the Ministerio de Economia, Industria $y$ Competitividad of Spain (project BIO2014-53508-R). We thank Dr Julio Rodríguez-Romero (CBGP-UPM-INIA, Madrid) for kind advice on handling Magnaporthe oryzae.

\section{References}

Ashraf M, Foolad MR. 2007. Roles of glycine betaine and proline in improving plant abiotic stress resistance. Environmental and Experimental Botany 59, 206-216.

Bárány I, Berenguer E, Solís MT, Pérez-Pérez Y, Santamaría ME, Crespo JL, Risueño MC, Díaz I, Testillano PS. 2018. Autophagy is activated and involved in cell death with participation of cathepsins during stress-induced microspore embryogenesis in barley. Journal of Experimental Botany 69, 1387-1402.

Barnabás B, Jäger K, Fehér A. 2008. The effect of drought and heat stress on reproductive processes in cereals. Plant, Cell \& Environment $\mathbf{3 1}$ 11-38.

Benchabane M, Schlüter U, Vorster J, Goulet MC, Michaud D. 2010. Plant cystatins. Biochimie 92, 1657-1666.

Beyene G, Foyer CH, Kunert KJ. 2006. Two new cysteine proteinases with specific expression patterns in mature and senescent tobacco (Nicotiana tabacum L.) leaves. Journal of Experimental Botany 57, 1431-1443.

Bi H, Kovalchuk N, Langridge P, Tricker PJ, Lopato S, Borisjuk N. 2017. The impact of drought on wheat leaf cuticle properties. BMC Plant Biology 17, 85

Botha AM, Kunert KJ, Cullis CA. 2017. Cysteine proteases and wheat (Triticum aestivum L) under drought: a still greatly unexplored association. Plant, Cell \& Environment 40, 1679-1690.

Bradford MM. 1976. A rapid and sensitive method for the quantitation of microgram quantities of protein utilizing the principle of protein-dye binding. Analytical Biochemistry 72, 248-254.

Buda GJ, Isaacson T, Matas AJ, Paolillo DJ, Rose JK. 2009. Threedimensional imaging of plant cuticle architecture using confocal scanning laser microscopy. The Plant journal 60, 378-385.

Chen HJ, Su CT, Lin CH, Huang GJ, Lin YH. 2010. Expression of sweet potato cysteine protease SPCP2 altered developmental characteristics and stress responses in transgenic Arabidopsis plants. Journal of Plant Physiology 167, 838-847.

Chen HJ, Tsai YJ, Shen CY, Tsai TN, Huang GJ, Lin YH. 2013. Ectopic expression of sweet potato cysteine protease SPCP3 alters phenotypic traits and enhances drought stress sensitivity in transgenic Arabidopsis plants. Journal of Plant Growth Regulation 32, 108-121.

Dawson IK, Russell J, Powell W, Steffenson B, Thomas WT, Waugh R. 2015. Barley: a translational model for adaptation to climate change. New Phytologist 206, 913-931.

de Ollas C, Arbona V, Gómez-Cadenas A. 2015. Jasmonoy isoleucine accumulation is needed for abscisic acid build-up in roots of Arabidopsis under water stress conditions. Plant, Cell \& Environment $\mathbf{3 8}, 2157-2170$

De Ollas C, Arbona V, Gómez-Cadenas A, Dodd IC. 2018. Attenuated accumulation of jasmonates modifies stomatal responses to water deficit. Journal of Experimental Botany 69, 2103-2116.

de Ollas C, Dodd IC. 2016. Physiological impacts of ABA-JA interactions under water-limitation. Plant Molecular Biology 91, 641-650.

Diaz-Mendoza M, Dominguez-Figueroa JD, Velasco-Arroyo B, et al. 2016a. HvPap-1 C1A protease and HvCPI-2 cystatin contribute to barley grain filling and germination. Plant Physiology 170, 2511-2524.

Díaz-Mendoza M, Velasco-Arroyo B, González-Melendi P, Martínez M, Díaz I. 2014. C1A cysteine protease-cystatin interactions in leaf senescence. Journal of Experimental Botany 65, 3825-3833.

Diaz-Mendoza M, Velasco-Arroyo B, Santamaria ME, Diaz I, Martinez M. 2017. HvPap-1 C1A protease participates differentially in the barley response to a pathogen and an herbivore. Frontiers in Plant Science 8, 1585.

Diaz-Mendoza M, Velasco-Arroyo B, Santamaria ME, GonzálezMelendi P, Martinez M, Diaz I. 2016b. Plant senescence and proteolysis: two processes with one destiny. Genetics and Molecular Biology 39, 329-338.

Gilroy EM, Hein I, van der Hoorn R, et al. 2007. Involvement of cathepsin $B$ in the plant disease resistance hypersensitive response. The Plant Journal 52, 1-13.

Grudkowska M, Zagdańska B. 2004. Multifunctional role of plant cysteine proteinases. Acta Biochimica Polonica 51, 609-624.

Guo Y, Gan SS. 2012. Convergence and divergence in gene expression profiles induced by leaf senescence and 27 senescence-promoting hormonal, pathological and environmental stress treatments. Plant, Cell \& Environment 35, 644-655.

Hensel G, Kastner C, Oleszczuk S, Riechen J, Kumlehn J. 2009. Agrobacterium-mediated gene transfer to cereal crop plants: current protocols for barley, wheat, triticale, and maize. International Journal of Plant Genomics 2009, 835608.

Höwing T, Huesmann C, Hoefle C, Nagel MK, Isono E, Hückelhoven R, GietI C. 2014. Endoplasmic reticulum KDEL-tailed cysteine endopeptidase 1 of Arabidopsis (AtCEP1) is involved in pathogen defense. Frontiers in Plant Science 5, 58.

Kempema LA, Cui X, Holzer FM, Walling LL. 2007. Arabidopsis transcriptome changes in response to phloem-feeding silverleaf whitefly nymphs. Similarities and distinctions in responses to aphids. Plant Physiology 143, 849-865.

Khanna-Chopra R, Srivalli B, Ahlawat YS. 1999. Drought induces many forms of cysteine proteases not observed during natural senescence. Biochemical and Biophysical Research Communications 255, 324-327.

Kidric M, Kos J, Sabotic J. 2014. Proteases and their endogenous inhibitors in the plant response to abiotic stress. Botanica Serbica $\mathbf{3 8}$, 139-158.

Kosma DK, Bourdenx B, Bernard A, Parsons EP, Lü S, Joubès J, Jenks MA. 2009. The impact of water deficiency on leaf cuticle lipids of Arabidopsis. Plant Physiology 151, 1918-1929.

Kunert KJ, van Wyk SG, Cullis CA, Vorster BJ, Foyer CH. 2015. Potential use of phytocystatins in crop improvement, with a particular focus on legumes. Journal of Experimental Botany 66, 3559-3570.

Leung H, Borromeo ES, Bernardo MA, Notteghem JL. 1988 Genetic analysis of virulence in the rice blast fungus Magnaporthe grisea. Phytopathology 78, 1227-1233.

Lischtenthaler HK. 1987. Chlorophylls and carotenoids, pigments of photosynthetic biomembranes. Methods in Enzymology 148, 350-382.

Livak KJ, Schmittgen TD. 2001. Analysis of relative gene expression data using real-time quantitative PCR and the $2^{-\Delta \Delta} C^{\top}$ method. Methods 25, 402-408.

Mahalingam R. 2017. Phenotypic, physiological and malt quality analyses of US barley varieties subjected to short periods of heat and drought stress. Journal of Cereal Science 76, 199-205.

Mahouachi J, Arbona V, Gomez-Cadena A. 2007. Hormonal changes in papaya seedlings subjected to progressive wáter stress and re-watering. Plant Growth Regulation 53, 43-51.

Marthe C, Kumlehn J, Hensel G. 2015. Barley (Hordeum vulgare L.) transformation using immature embryos. Methods in Molecular Biology $1223,71-83$.

Martinez M, Cambra I, Carrillo L, Diaz-Mendoza M, Diaz I. 2009. Characterization of the entire cystatin gene family in barley and their target cathepsin L-like cysteine-proteases, partners in the hordein mobilization during seed germination. Plant Physiology 151, 1531-1545.

Martínez M, Cambra I, González-Melendi P, Santamaría ME, Díaz I. 2012. C1A cysteine-proteases and their inhibitors in plants. Physiologia Plantarum 145, 85-94.

Martinez M, Diaz I. 2008. The origin and evolution of plant cystatins and their target cysteine proteinases indicate a complex functional relationship. BMC Evolutionary Biology 8, 198.

Martinez M, Santamaria ME, Diaz-Mendoza M, Arnaiz A, Carrillo L, Ortego F, Diaz I. 2016. Phytocystatins: defense proteins against phytophagous insects and acari. International Journal of Molecular Sciences 17, 1747

Moraes EP, Rupérez FJ, Plaza M, Herrero M, Barbas C. 2011 Metabolomic assessment with CE-MS of the nutraceutical effect of Cystoseira spp extracts in an animal model. Electrophoresis 32 2055-2062. 
Osakabe Y, Osakabe K, Shinozaki K, Tran LS. 2014. Response of plants to water stress. Frontiers in Plant Science 5, 86.

Parrott DL, Martin JM, Fischer AM. 2010. Analysis of barley (Hordeum vulgare) leaf senescence and protease gene expression: a family C1A cysteine protease is specifically induced under conditions characterized by high carbohydrate, but low to moderate nitrogen levels. New Phytologist 187, 313-331.

Pechan T, Cohen A, Williams WP, Luthe DS. 2002. Insect feeding mobilizes a unique plant defense protease that disrupts the peritrophic matrix of caterpillars. Proceedings of the National Academy of Sciences, USA 99, 13319-13323.

Quain MD, Makgopa ME, Márquez-García B, Comadira G, Fernandez-Garcia N, Olmos E, Schnaubelt D, Kunert KJ, Foyer CH. 2014. Ectopic phytocystatin expression leads to enhanced drought stress tolerance in soybean (Glycine max) and Arabidopsis thaliana through effects on strigolactone pathways and can also result in improved seed traits. Plant Biotechnology Journal 12, 903-913.

Rabbani MA, Maruyama K, Abe H, Khan MA, Katsura K, Ito Y, Yoshiwara K, Seki M, Shinozaki K, Yamaguchi-Shinozaki K. 2003. Monitoring expression profiles of rice genes under cold, drought, and highsalinity stresses and abscisic acid application using CDNA microarray and RNA gel-blot analyses. Plant Physiology 133, 1755-1767.

Rawlings ND, Barrett AJ, Thomas PD, Huang X, Bateman A, Finn RD. 2018. The MEROPS database of proteolytic enzymes, their substrates and inhibitors in 2017 and a comparison with peptidases in the PANTHER database. Nucleic Acids Research 46, D624-D632.

Roberts IN, Caputo C, Criado MV, Funk C. 2012. Senescenceassociated proteases in plants. Physiologia Plantarum 145, 130-139.

Sah SK, Reddy KR, Li J. 2016. Abscisic acid and abiotic stress tolerance in crop plants. Frontiers in Plant Science 7,571.

Santamaria ME, Diaz I, Martinez M. 2018a. Dehydration stress contributes to the enhancement of plant defense response and mite performance on barley. Frontiers in Plant Science 9, 458.

Santamaria ME, Diaz-Mendoza M, Perez-Herguedas D, Hensel G, Kumlehn J, Diaz I, Martinez M. 2018b. Overexpression of Hvlcy6 in barley enhances resistance against Tetranychus urticae and entails partial transcriptomic reprogramming. International Journal of Molecular Science 19, 697.

Santamaría ME, Martinez M, Arnaiz A, Ortego F, Grbic V, Diaz I. 2017. $\mathrm{MATI}$, a novel protein involved in the regulation of herbivore-associated signaling pathways. Frontiers in Plant Science 8, 975.

Shi H, Wang B, Yang P, Li Y, Miao F. 2016. Differences in sugar accumulation and mobilization between sequential and non-sequential senescence wheat cultivars under natural and drought conditions. PLoS ONE 11, e0166155.
Shindo T, Misas-Villamil JC, Hörger AC, Song J, van der Hoorn RA. 2012. A role in immunity for Arabidopsis cysteine protease RD21, the ortholog of the tomato immune protease C14. PLOS ONE 7, e29317.

Shindo T, Van der Hoorn RA. 2008. Papain-like cysteine proteases: key players at molecular battlefields employed by both plants and their invaders. Molecular Plant Pathology 9, 119-125.

Simova-Stoilova L, Vaseva I, Grigorova B, Demirevska K, Feller U. 2010. Proteolytic activity and cysteine protease expression in wheat leaves under severe soil drought and recovery. Plant Physiology and Biochemistry 48, 200-206.

Sueldo DJ, van der Hoorn RAL. 2017. Plant life needs cell death, but does plant cell death need Cys proteases? The FEBS Journal 284, 1577-1585.

Tan Y, Li M, Yang Y, Sun X, Wang N, Liang B, Ma F. 2017. Overexpression of MpCYS4, a phytocystatin gene from Malus prunifolia (Willd.) Borkh., enhances stomatal closure to confer drought tolerance in transgenic Arabidopsis and apple. Frontiers in Plant Science 8, 33.

Thomas EL, van der Hoorn RAL. 2018. Ten prominent host proteases in plantpathogen interactions. International Journal of Molecular Sciences 19, 639.

van der Hoorn RA. 2008. Plant proteases: from phenotypes to molecular mechanisms. Annual Review of Plant Biology 59, 191-223.

Velasco-Arroyo B, Diaz-Mendoza M, Gandullo J, Gonzalez-Melendi P, Santamaria ME, Dominguez-Figueroa JD, Hensel G, Martinez M, Kumlehn J, Diaz I. 2016. HvPap-1 C1A protease actively participates in barley proteolysis mediated by abiotic stresses. Journal of Experimental Botany 67, 4297-4310.

Velasco-Arroyo B, Diaz-Mendoza M, Gomez-Sanchez A, MorenoGarcia B, Santamaria ME, Torija-Bonilla M, Hensel G, Kumlehn J, Martinez M, Diaz I. 2018. Silencing barley cystatins HvCPI-2 and $\mathrm{HvCPI}-4$ specifically modifies leaf responses to drought stress. Plant, Cell \& Environment 41, 1776-1790.

Wang W, Zhou XM, Xiong HX, Mao WY, Zhao P, Sun MX. 2018. Papain-like and legumain-like proteases in rice: genome-wide identification, comprehensive gene feature characterization and expression analysis. BMC Plant Biology 18, 87

Xue D, Zhang X, Lu X, Chen G, Chen ZH. 2017. Molecular and evolutionary mechanisms of cuticular wax for plant drought tolerance. Frontiers in Plant Science 8, 621

Yeats TH, Rose JK. 2013. The formation and function of plant cuticles. Plant Physiology 163, 5-20.

Zang QW, Wang CX, Li XY, Guo ZA, Jing RL, Zhao J, Chang XP. 2010. Isolation and characterization of a gene encoding a polyethylene glycol-induced cysteine protease in common wheat. Journal of Biosciences 35, 379-388.

Zhang X, Liu S, Takano T. 2008. Two cysteine proteinase inhibitors from Arabidopsis thaliana, AtCYSa and AtCYSb, increasing the salt, drought, oxidation and cold tolerance. Plant Molecular Biology 68, 131-143. 